\title{
ANALISIS PENGAWASAN PETUGAS SAFETY DENGAN KEPATUHAN PENGGUNAAN ALAT PELINDUNG DIRI (APD) DI PROYEK PEMBANGUNAN APARTEMAN MARIGOLD AT NAVA PARK
}

\author{
Ita La Tho ${ }^{1)}$, Fenita Purnama Sari Indah ${ }^{1)}$, Lela Kania Rahsa Puji ${ }^{1)}$ \\ ${ }^{1}$ STIKes Kharisma Persada, Pamulang Tangerang Selatan \\ ithafarzamto@gmail.com
}

\begin{abstract}
ABSTRAK
Alat pelindung diri merupakan salah satu sarana untuk mengurangi terjadinya kecelakaan kerja pada pekerja, dan dimana sakarang lebih maju dari tahun ke tahun alat pelindung diri semakin canggih untuk digunakan. Penelitian ini bertujuan untuk menganalisis hubungan pengawasan petugas safety dengan kepatuhan pemakaian alat pelindung diri (APD) pada Pekerja Proyek Pembangunan Apartemen Marigold at Nava Park. Penelitian ini menggunakan observasional analitik yang bertujuan untuk memperoleh penyebab tentang hubungan pengawasan petugas safety dan sikap dengan kepatuhan penggunaan alat pelindung diri (APD) Desain penelitian yang digunakan adalah cross sectional. Hasil penelitian menunjukkan bahwa terdapat hubungan pengawasan petugas safety dengan kapatuhan penggunaan alat pelindung diri di Proyek Pembangunaan Apartemen Marigold at Nava Park (Pvalue=0,018), nilai OR 3,88. Perusahaan perlu mengadakan pelatihan terhadap karyawan dalam penggunaan dan perawatan alat pelindung diri, serta memberikan perhatian lebih atau penuh dalam pencegahan dan pengendalian kecelakaan kerja.
\end{abstract}

Kata Kunci :Keselamatan Kerja, APD, Kepatuhan

\section{PENDAHULUAN}

Latar Belakang Penelitian

Berdasarkan data Internasional Labour Organization (ILO) pada Tahun 2015 setiap hari terjadinya kecelakan kerja sekitar 6.000 kasus. Yang mengakibatkan korban fatal di dunia, sedangkan di Indonesia sendiri pada tahun 2015 terdapat 20 kasus kecelakaan kerja yang di alami para buruh dari setiap 100 ribu tenaga kerja. Tercatat bahwa angka kecelakaan kerja cukup tinggi di Indonesia. Data pada Badan Penyelenggara Jaminan Sosial (BPJS) Ketenagakerjaan mengatakan bahwa sampai akhir tahun 2015 kecelakaan kerja telah mencapai sebanyak 105.182 kasus yang mencakup jumlah kecelakaan berat mencapai 2.375 kasus. Kecelakaan berat tersebut menyebabkan kematian.

Menurut Dirjen Pembinaan Pengawasan Ketenagakerjaan dan Keselamatan dan Kesehatan Kerja (PPK dan K3) Kementerian Ketenaga kerjaan (Kemnaker) jumlah kecelakaan kerja dari tahun ke tahun mengalami tren peningkatan. Pada total jumlah kecelakaan kerja setiap tahunnya mengalami peningkatan hingga 5\%. Pada kecelakaan kerja berat tren peningkatannya cukup besar yakni sekitar 5\%10\% setiap tahunnya (BPJS 2016 ).

Kerja yang memiliki intensitas cukup tinggi adalah ciri pada sektor yang bergerak di dunia konstruksi. Penyerapan tenaga kerja yang diserap di sektor ini pun sangat besar, pada tahun 2009 berjumlah 5,4 juta jiwa atau 5,3\% dari tenaga kerja nasional. Peningkatan terus terjadi hingga 5,8 juta jiwa di 2011. Prediksi yang dikemukakan Kementerian Pekerjaan Umum mengatakan bahwa setelah tahun 2012, jumlah tenaga kerja pada sector ini akan mencapai lebih dari 6 juta orang. Data menyebutkan bahwa pada kasus kecelakaan kerja, hampir $32 \%$ berasal dari sektor konstruksi. (KemenPu di kutip dalam Agustine 2015).

PT Bumi Parama Wisesa (BPW) adalah perusahaan joint venture antara Sinarmas Land dan Hongkong Land. Perjanjian kerja sama itu sudah dilakukan sejak akhir tahun 2012 dengan komposisi kepemilikan saham $51 \%$ Sinarmasland dan 49\% Hongkong Land. PT. Bumi Parama Wisesa menghadirkan hunian premium, Marigold Condominium, yang dibangun dengan konsep premium lifestyle to enjoy, dikawasan Navapark, BSD City, Jelupang, Kabupaten Tangerang. 
Berdasarkan hasil penelitian yang dilakukan di PT. Bumi Parama Wisesa terkait kasus kejadian kecelakaan kerja terdapat 7 kasus selama tahun 2017 dengan jumlah pekerja 241 pekerja. Kasus kecelakaan kerja yang sering di alami oleh PT. Bumi Parama Wisesa yaitu seperti terluka saat pemasangan besi untuk pengecoran, terinjak paku dan jari terjepit benda tajam. Terjadinya kecelakaan kerja di bagian pemasangan besi pada saat pengecoran di sebabkan pekerja tidak menggunakan alat pelindung diri (APD) yaitu sarung tanggan untuk melindungi tangannya sehingga besi tersebut menusuk ke bagian tangan. Banyak pekerja yang tidak mematuhi peraturan yang telah di tetapkan oleh perusahaan selain itu perusahaan sudah memasangkan spanduk K3 baik tetapi masih terdapat beberapa tenaga kerja yang kurang kesadarannya dalam hal kepatuhan peraturan K3, terutama dalam hal penggunaan alat pelindung diri, dengan alasan ketidak nyamanan penggunaan alat pelindung diri.

PT. Bumi Parama Wisesa mempunyai pekerja sebanyak 241 pekerja dan PT. Bumi parama wisesa juga mempunyai program K3 seperti Safety Induction, Safety Morning, Inspeksi K3 Safety Patrol, Safety Sweeping/ Screening Pagi. Meskipun PT.Bumi Parama Wisesa juga sudah mempunyai programprogram K3 bukan berarti kecelakaan di PT. Bumi parama wisesa tidak terjadi ataupun (zero accident). Masih banyak pekerja yang lalai dan tidak mematuhi peraturan yang berada di PT. Bumi Parama Wisesa. Pihak Perusahaan juga sudah menyediakan alat pelindung diri (APD) sesuai dengan standar K3 perusahaan antara lain: helm, rompi dan sepatu yang di berikan kepada seluruh pekerja sebelum bekerja.

\section{Perumusan Masalah}

Berdasarkan latar belakang tersebut, maka rumusan masalah dalam penelitian adalah apakah terdapat hubungan pengawasan petugas safety dengan Kepatuhan Penggunaan Alat Pelindung Diri (APD) di Proyek Pembangunan Apartemen Marigold At Nava Park?

\section{Tujuan Penelitian}

Penelitian ini bertujuan untuk menganalisis hubungan pengawasan petugas safety dengan Kepatuhan Penggunaan Alat Pelindung Diri
(APD) di Proyek Pembangunan Apartemen Marigold At Nava Park

\section{Kontribusi Penelitian}

Kontribusi penelitian ini terutama kepada kontribusi ke pengetahuan, yaitu untuk menggambarkan dan memberikan informasi bahwa peran pengawas petugas safety dalam melakukan supervisi sangat penting. Hal ini dilakukan agar para pekerja patuh dalam menggunakan APD sehingga kecelakaan kerja dapat dicegah.

\section{DASAR TEORI}

Telaah literatur penelitian menjelaskan mengenai Alat Pelindung Diri (APD)

\section{Alat Pelindung Diri}

1. Pengertian alat pelindung diri

Alat pelindung diri (APD) merupakan alat yang digunakan oleh para pekerja untuk melindungi diri dari situasi bahaya yang terdapat pada pekerjaan. Alat pelindung diri adalah salah satu cara yang digunakan untuk mencegah terjadinya kecelakaan kerja. secara teknis alat pelindung diri tidaklah sempurna untuk melindungi pekerja saat bekerja, akan tetapi bisa mengurangi tingkat keparahan dari terjadinya kecelakaan akibat kerja (Rohman, 2015).

2. Alat Pelindung Diri pada BidangKonstruksi

Alat Pelindung Diri yang digunakan khususnya dalam bidang konstruksi yang dipakai sesuai dengan jenis pekerjaannya adalah sebagai berikut: (Alamsyah, 2014)

a. Alat Pelindung Kepala (Head Protector)

b. Alat Pelindung Muka dan Mata

c. Alat Pelindung Telinga

d. Alat pelindung pernafasan

e. Alat Pelindung Kaki 
f. Alat pelindung tangan

g. Body Harness h.

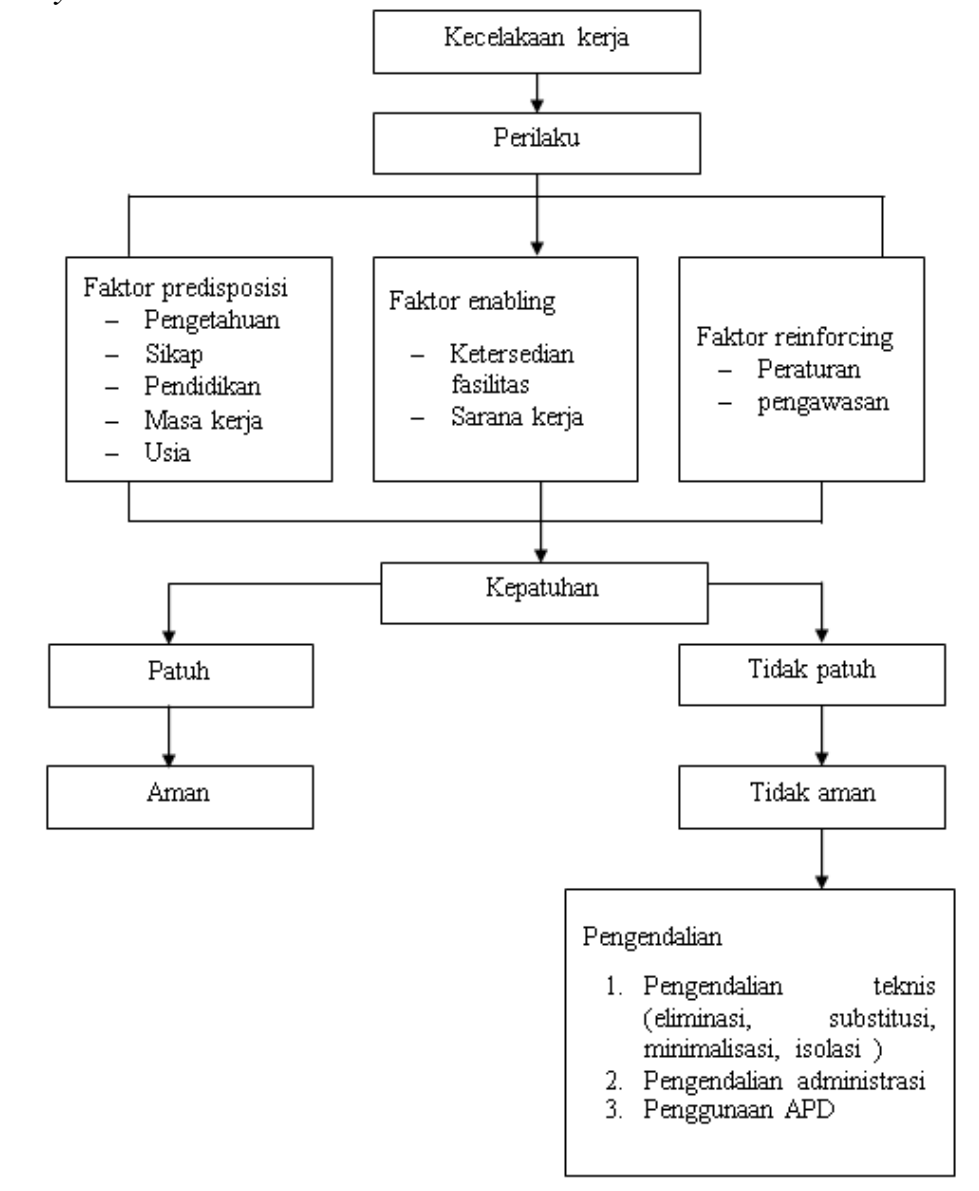

Gambar 2.2 Kerangka teori

(Sumber : Umar Fahmi 2014, Saifuddin Azwar 2005. Tarwaka 2008, Sinta Fitriani 2011, Suma'mur 2009, Sutrisno 2010, Ramli 2010, Notoatmodjo 2007, Gempur Santoso 2004, Tulus Winarsunu 2008)

\section{METODOLOGI PENELITIAN}

Jenis penelitian ini menggunakan observasional analitik yang bertujuan untuk menganalisis hubungan pengawasan petugas safety dengan kepatuhan penggunaan alat pelindung diri (APD). Desain penelitian yang digunakan adalah cross sectional Populasi dalam penelitian ini adalah seluruh subjek atau seluruh pekerja bangunan di Proyek Pembangunan Apartemen Marigold At Nava Park sebanyak 241 orang. Sampel dalam penelitian ini berjumlah 71 responden. Teknik pengambilan sample dalam penelitian ini dengan menggunakan teknik probability sampling (Random Sampling) yaitu Simple Randon Sampling. Hipotesis penelitian ini yaitu terdapat hubungan pengawasan petugas safety dengan Kepatuhan Penggunaan Alat Pelindung
Diri (APD) di Proyek Pembangunan Apartemen Marigold At Nava Park.

Intrumen yang di gunakan pada penelitian ini adalah menggunakan kuesioner, yaitu memberikan seperangkat pertanyaan kepada responden untuk di jawab dalan lembar kuesioner. Uji validitas dan reabilitas di lakukan di PT. Bumi Parama Wisesa di area pembesian. Di pekerja pembesian terdapat 45 pekerja. Dalam uji Validitas dan Reliabilitas peneliti mengambil 30 pekerja untuk di ujikan. Jenis dan sumber data yang dikumpulkan dalam penelitian ini adalah data primer (pengawasan petugas safety serta kepatuhan pekerja dalam menggunakan alat pelindung diri (APD)) dan data sekunder (jumlah pekerja dan usia pekerja di Proyek Pembangunan Apartemen Marigold at Nava Park). 


\section{ANALISIS PEMBAHASAN \\ DATA \\ DAN}

Menguraikan analisis data penelitian dan deskriptif statistik yang diperlukan dalam penelitian baik penelitian kuantitatif maupun penelitian kualitatif yang di dalamnya membutuhkan dukungan analisis data.

Analisis Univariat
Analisis univariat dapat digunakan dengan tujuan mendapatkan distribusi frekuensi variabel dependen (kepatuhan penggunaan APD) dan variabel independen (pengawasan petugas safety).

a. Pengawasan Petugas Safety

Berdasarkan penelitian yang di lakukan di Proyek Pembangunan Apartemen Marigold at Nava Park menurut distribusi pengawasan Pengawasan petugas safety sebagai berikut :

Tabel 1. Distribusi frekuensi berdasarkan pengawasan petugas safety pada pekerja di Proyek Pembangunan Apartemen Marigold at Nava Park

\begin{tabular}{ccc}
\hline Pengawasan & Frekuensi & \% \\
\hline Ada & 39 & 54,9 \\
\hline Tidak ada & 32 & 45,1 \\
\hline Total & 71 & 100,0
\end{tabular}

Sumber :Data Primer (2018)

Berdasarkan tabel 1 dari jumlah 71 responden, di dapatkan sebagian besar responden yang menjawab ada sebanyak 39 responden dengan jumlah persentase sebesar $(54,9 \%)$.

b. Kepatuhan Penggunaan APD
Berdasarkan penelitian yang di lakukan Proyek Pembangunan Apartemen Marigold at Nava Park kota tangerang distribusi kepatuhan penggunaan APD sebagai berikut

Tabel 2. Distribusi frekuensi berdasarkan kepatuhan penggunaan APD pada pekerja di Proyek Pembangunan Apartemen Marigold at Nava Park

\begin{tabular}{ccc}
\hline Kepatuhan & Frekuensi & \% \\
\hline Patuh & 40 & 56,3 \\
\hline Tidak patuh & 31 & 43,7 \\
\hline Total & 71 & 100,0
\end{tabular}

Sumber :Data Primer (2018)

Berdasarkan tabel 2, dari jumlah 71 responden, sebagaian besar pekerja memiliki kepatuhan penggunaan alat pelindung diri sebanyak 40 responden dengan jumlah persentase sebesar $(56,3 \%)$

\section{Uji Bivariat Hubungan Pengawasan Petugas}

Safety dengan kepatuhan penggunaan APD

Berdasarkan uji statistic yang di dapatkan di Proyek Pembangunan Apartemen Marigold at Nava Park pada Tabel sebagai berikut :

Tabel 3. Hubungan antara pengawasan APD Dengan Kepatuhan penggunaan APD Pada PekerjaProyek Pembangunan Apartemen Marigold at Nava Park 


\begin{tabular}{|c|c|c|c|c|c|c|c|c|}
\hline \multirow[b]{2}{*}{ Pengawasan } & \multicolumn{4}{|c|}{ Kepatuhan } & \multirow[b]{2}{*}{ Jumlah } & \multirow[b]{2}{*}{$\%$} & \multirow[b]{2}{*}{$\begin{array}{c}P- \\
\text { Value }\end{array}$} & \multirow[b]{2}{*}{ OR } \\
\hline & Patuh & $\%$ & $\begin{array}{l}\text { Tidak } \\
\text { patuh }\end{array}$ & $\%$ & & & & \\
\hline Ada & 27 & 69,2 & 12 & 30,8 & 39 & 100 & \multirow{3}{*}{0,029} & \multirow{3}{*}{$\begin{array}{c}3,288 \\
(1,234- \\
8761)\end{array}$} \\
\hline Tidak ada & 13 & 40,6 & 19 & 59,4 & 32 & 100 & & \\
\hline Total & 40 & 56,3 & 31 & 43,7 & 71 & 100 & & \\
\hline
\end{tabular}

\section{Sumber :Data Primer (2018)}

Dari tabel 3, menunjukkan bahwa dengan adanya pengawasan dengan jawaban patuh sebanyak 27 responden $(69,2 \%)$ Sedangkan Responden dengan pengawasan yang tidak ada tetapi patuh sebanyak 13 responden dengan jumlah persentase sebesar $(40,6 \%)$. Hasil uji statistik didapatkan $p$-value 0,029 pada $\alpha=0,05$ dan OR 3,288 (1,234-8761) nilai dapat disimpulkan bahwa ada hubungan yang bermakna antara sikap dengan kepatuhan penggunaan alat pelindung diri (APD) di proyek pembangunan Apartemen Marigold at Nava park.

Pengawasan merupakan kegiatan mengendalikan tenaga kerja agar mentaati peraturan organisasi dan berkerja sesuai dengan rencana. Pengawasan dalam kepatuhan menggunakan alat pelindung diri saat bekerja dikuatkan dengan Pemenakertrans No.per.03/Men/1982 yang menyatakan bahwa pembinaan dan pengawasan perlengkapan untuk kesehatan tenaga kerja.

Salah satu tujuan dilakukan pengawasan yaitu untuk meningkatkan kedisiplinan pekerja untuk menggunakan alat pelindung diri selama melakukan pekerjaan, selain itu juga bisa memberi hukuman atau teguran yang keras kepada pekerja yang tidak menggunakan alat pelindung diri saat bekerja. Sehingga perilaku pekerja akan menjadi lebih baik dengan adanya pengawasan dari perusahaan atau pihak-pihak yang terkait.

Penelitian ini sejalan dengan penelitian yang dilakukan oleh Sudarmo, Zairin Noor Helmi, dan Lenie Marlinael (2014) Terdapat

\section{DAFTAR PUSTAKA}

Adailah, Binthan. 2016. Definisi dan Pengertian Kecelakaan Kerja Serta Latar pengaruh yang signifikan pengawasan perawat dan ketersediaan APD terhadap kepatuhan penggunaan APD di IBS RSUD Ulin Banjarmasin dengan nilai kofisien regresi sebesar 0,678. Penelitian ini juga sejalan dengan penelitian yang dilakukan oleh Arianto Wibowo (2010) yang menunjukan ada hubungan yang bermakna antara pengawasan dengan kepatuhan penggunaan alat pelindung diri (APD) dengan $p=0,000 \quad(p$-value $<0,05)$ dengan OR 32,533 (10,535-100.468). Pengawasan terhadap aktivitas pekerja diharapkan dapat menumbuhkan kepatuhan dan kesadaran akan pentingnya keselamatan dan kesehatan kerja bagi dirinya, pekerja lain, dan lingkungan kerjanya.

\section{KESIMPULAN}

Berdasarkan hasil uji statistik dapat disimpulkan bahwa ada hubungan yang bermakna antara pengawasan petugas safety dengan kepatuhan penggunaan alat pelindung diri (APD) di Proyek Pembangunan Apartemen Marigold at Nava Park dengan p-value 0,029 pada $\alpha=0,05$ dan OR 3,288 (1,234-8761). Sebaiknya Perusahaan meningkatkan pengawasan tentang pemakaian alat pelindung diri yang digunakan oleh karyawan yang sudah disediakan oleh perusahaan. Sehingga alat pelindung diri yang disediakan seperti masker, sarung tangan, sepatu karet dan hlem selalu digunakan pekerja saat melakukan pekerjaannya dan sesuai kebutuhan karyawan. 
https://www.scribd.com/doc/29383482 2/Definisi-Dan-Pengertian-

Kecelakaan-Kerja-Serta-Latar-

Belakang-Faktor-Terjadinya-

Kecelakaan-Kerja (di akses tanggal 1602-2018 )

Agustine, Stefanie. 2016. Training Material Keselamatan Dan Kesehatan Kerja Bidang

Kesehatan KerjaHttp://Lib.Ui.Ac.Id/Fi le?File=Digital/2016-4/20405319-SP-

Stefanie\%20Agustine.Pdf (di akses tanggal 13-02-2018)

Ahmad Dahlan. 2017. Definisi populasi sampel dan teknik pengambilan sampel dalam penelitian

https://www.ahmaddahlan.net/2017/09 /defenisi-populasi-pengertian-sampelteknik-jenis-metode-sampling.html (di akses tanggal 02-03-2018)

Alamsyah, Bahtiar. 2014. Makalah Kesehatan Dan Keselamatan Kerja (K3) Dalam Bidang Alat Perlindungan Diri (APD)Http://Www.Academia.Edu/100 60361/MAKALAH_Kesehatan_Dan_ Keselamatan_Kerja_K3_Dalam_Bidan g_Alat_Perlindungan_Diri_APD(di akses tanggal 13-02-2018)

Arikunto S, 2006. Prosedur Penelitian Suatu Pendekatan Praktik, Ed Revisi VI, Penerbit PT Rineka Cipta, Jakarta.

Arikunto, S. 2010. Prosedur Penelitian Suatu

Pendekatan Praktik. Jakarta: Rineka Cipta

Azwar, Fery. 2017. Pengertian sikap menurut para alhi https://www.scribd.com/doc/25911280 0/sikap (13-02-2018 11.29)

Azwar. 2011, Sikap Manusia: Teori dan Pengukurannya. Yogyakarta: Pustaka Pelajar.

Azwar. 2005. Sikap manusia. Yogyakarta : Pustaka Pelajar.

Badan Penyelenggara Jaminan Sosial. 2016. Http://Www.Bpjsketenagakerjaan.Go.I d/Berita/5769/Jumlah-KecelakaanKerja-Di-Indonesiamasih-Tinggi.Html (02-04-2018 10.42)

Badan Penyelenggara Jaminan Sosial. 2016. https://finance.detik.com/beritaekonomi-bisnis/d-3900099/kemnakergandeng-ilo-tingkatkan-kualitaspengawas-tenaga-kerja (di akses tanggal 13-02-2018)
Bambang. 2017. Penjelasan suhu dan faktor yang mempengaruhinya https://www.sobatgeo.me/2017/01/pen jelasan-suhu-udara-dan-faktoryang.html (di akses tanggal 27-032018)

Barizqi, Inna Nesyi. 2016. Hubungan Antara Kepatuhan Penggunaan Apd Dengan Kejadian Kecelakaan Kerja Pada Pekerja Bangunan Pt. Adhi Karya Tbk Proyek Rumah Sakit Telogorejo Semarang

File:///C:/Users/Bismillah/Downloads/ 123dok_Hubungan_Antara_Kepatuhan _Penggunaan_Apd_Dengan_Kejadian _Kecelakaan_Kerja_Pada_Pekerja_Ba ngunan_Pt.Pdf (di akses tanggal 16-032018)

Cahya. 2016. Pengertian jenis kelamin http://karyatulisilmiah.com/pengertianjenis-kelamin/ (di akses tanggal 16-032018)

Fahmi, umar. 2014. kesehatan masyarakat teori dan aplikasi. Jakarta : PT. Raja Grafindo persada.

Faniah, Aniek Masri. 2016. Faktor-Faktor Yang Berhubungan Dengan Kepatuhan Penggunaan Apd Earplug Dan Sarung Tangan Pada Pekerja Unit Perbaikan Di Pt. Kai Daop Vi Yogyakarta Dipo Solo Balapan Http://Eprints.Ums.Ac.Id/47765/1/Nas kah\%20publikasi.Pdf (di akses tanggal 27-03-2018)

Fitriani, sinta. 2011. Promosi kesehatan. Yogyakarta : Graha ilmu.

Hartono, Benny. 2016. Memory Alat Pelindung Diri Http://Staff.Memory-

Diy.Com/Training/WpContent/Uploads/2016/11/MATERIALAT-PELINDUNG-DIRI-

Training.Pdf APD (di akses tanggal 0203-2018)

Ilham. 2016. Faktor-faktor yang berhubungan dengan perilaku pekerja dalam penggunaan alat pelindung diri (APD) pada industri pengelasan informal di kelurahan gondrong, kecamatan cipondoh, kota tangerang tahun 2013 Http://Repository.Uinjkt.Ac.Id/Dspace /Bitstream/123456789/24269/1/Ilham $\%$ 20Noviandry-Fkik.Pdf (di akses tanggal 27-03-2018) 
Infodatin Pusat Data Dan Informasi Kementrian Kesehatan RI. 2015. Http://Www.Depkes.Go.Id/Resources/ Download/Pusdatin/Infodatin/Infodati n-Kesja.Pdf (di akses tanggal 02-03$1=2018$ )

Internasional labour organization ILO. 2015. Http://Www.Safetyshoe.Com/Tag/Data -Kecelakaan-Kerja-Tahun-2015-

Menurut-Ilo/ (di akses tanggal 17-022018)

Iryawan, indra. 2013. Pengertian umur dan katagori menurut depkes https://www.scribd.com/doc/16268592 1/usia-menurut-depkes (di akses tanggal 17-04-2018)

Jatmiko, Fauzi. 2017. Hubungan antara tingkat pengetahuan dan pengawasan terhadap perilaku pemakaian apd pada pekerja konstruksi pt wika beton boyolali file:///C:/Users/Bismillah/Downloads/1 272-2770-1-SM\%20(1).pdf (di akses tanggal 17-04-2018)

Kementerian Kesehatan Republik Indonesia 2015.

Http://Www.Depkes.Go.Id/Pdf.Php?Id $=201411030005$ (di akses tanggal 1302-2018)

Kementrian Kesehatan Republik Indonesia 2015.

Http://Www.Depkes.Go.Id/Article/Pri nt/201411030005/1-Orang-Pekerja-DiDunia-Meninggal-Setiap-15-Detik-

Karena-Kecelakaan-Kerja.Html (di akses tanggal 27-03-2018)

Liambo, Indri Syafitri Dewi, Yasnani. 2017. Faktor yang berhubungan dengan perilaku penggunaan alat pelindung diri (apd) pada tenaga teknisi pt pln (persero) wilayah sulselrabar sektor pembangkitan kendari unit pltd wuawua kota kendari tahun 2017 https://media.neliti.com/media/publicat ions/186941-ID-faktor-yang-

berhubungan-dengan-perilaku.pdf (di akses tanggal 27-02-2018)

Lyceum.2017.Teori Tentang Sikap Dan Model Pembentukan Sikap https://www.lyceum.id/teori-tentangsikap/ (di akses tanggal 03-04-2018)

Notoatmaodjo Soekidjo.2010. Metodologi Penelitian Kesehatan.Jakarta:Rineka Cipta Karya
Notoatmaodjo, Soekidjo. 2007. promosi kesehatan dan ilmu perilaku. jakarta : PT. Rineka Cipta

Osha. 2016. kesehatan dan keselamatan kerja http://www.safetyshoe.com/tag/sebabsebab-terjadinya-kecelakaan-kerja/ (di akses tanggal 27-03-2018)

Panggabean, Putri Kartika 2016. Pengaruh Penyuluhan K3 Tentang Apd Terhadap Pengetahuan Dan Sikap Petani Jeruk Dalam Penggunaan Apd Di Desa Suka Sipilihen Kabupaten Karo Tahun 2016 Http://Repository.Usu.Ac.Id/Bitstream /Handle/123456789/59331/Cover.Pdf? Sequence $=7$ (di akses tanggal 16-022018)

Plengdut. 2015. Beberapa Jenis Kerugian yang Ditimbulkan Oleh Kecelakaan Kerja https://www.plengdut.com/beberapajenis-kerugian-yang-ditimbulkan-olehkecelakaan-kerja/5643/ (di akses tanggal 13-02-2018)

Pratama, Putri Inda. 2017. Tugas K3 Dan Hukum Perburuhan Makalah Program K3 Di Perusahaan Tambang Https://Www.Scribd.Com/Document/3 64603782/Makalah-K3-Di-

Perusahaan-Tambang-Inda-PratamaPutri-1031411029-Teknik-

Pertambangan-Ubb-Vi-Av (di akses tanggal 02-03-2018)

Puji, Andri Dwi, Bina Kurniawan, Siswi Jayanti. 2017. File:///C:/Users/Bismillah/Downloads/ 18863-38190-1-SM.Pdf (di akses tanggal 02-04-2018)

Ramli, soehatman. 2010. Sistem manajemen keselamatan dan kesehatan kerja OHSAS 18001. jakarta: Dian Rakyat. (di akses tanggal 16-02-2018)

Riadi, Muchlisin. 2017. Pengertian, Jenis, Penyebab dan Pencegahan Kecelakaan Kerja https://www.kajianpustaka.com/2017/1 2/pengertian-jenis-penyebabpencegahan-kecelakaan-kerja.html(di akses tanggal 13-022018)

Rohman, Muhammad Diky Fatkhur. 2015. Faktor-Faktor Yang Mempengaruhi Tingkat Kepatuhan Pemakaian Apd Pada Karyawan Di Pt. Pura Barutama Unit Paper Mill 5/6/9 Kudus 2015 Http://Mahasiswa.Dinus.Ac.Id/Docs/S 
kripsi/Abstrak/16389.Pdf (di akses tanggal 02-03-2018)

Santoso, gempur. 2004. Manajemen keselamatan dan kesehatan kerja , jakarta

Satria. 2016 teori konsep motivasi (pengertian, jenis, faktor dan proses motivasi menurut para ahli) http://www.materibelajar.id/2016/04/te ori-konsep-motivasi-pengertianjenis.html\# (di akses tanggal 03-042018)

Setiyawati, Siti Dessy .2016. Penerapan Penggunaan Alat Pelindung Diri Sebagai Upaya Perlindungan Terhadap Tenaga Kerja Di Pt Bayer Indonesia Bayer Cropsceince Https://Eprints.Uns.Ac.Id/4036/1/1536 42008201002141.Pdf (di akses tanggal 27-02-2018)

Sihombing, Dameyanti. 2016. Implementasi Keselamatan Dan Kesehatan Kerja (K3) Pada Proyek Di Kota Bitung (Studi Kasus Proyek Pembangunan Pabrik Minyak Pt.Mns) Https://Media.Neliti.Com/Media/Publi cations/130998-ID-Implementasi-

Keselamatan-Dan-Kesehatan-K.Pdf (di akses tanggal 17-04-2018)

Sufandi. 2016. Pengetian dan tujuan pengawasan

http://repository.usu.ac.id/bitstream/ha ndle/123456789/23484/Chapter\%20II; jsessionid=DE6BA0350B6678C $32 \mathrm{CF}$ 4712D1315C980? sequence $=3$ (di akses tanggal 17-04-2018)

Sugihartono. 2016. Alat pelindung dirihttps://www.scribd.com/document/ 374456979/320966049-Alat-

Pelindung-Diri-docx (di akses tanggal 16-02-2018)

Suma'mur, 2009. Higene perusahaan dan kesehatan kerja jakarta: PT. Toko gunung agung.

Suparyanto. (2010). Konsep Kepatuhan http://digilib.unimus.ac.id/files/disk1/1 55/jtptunimus-gdl-umicholifa-7716-7daftarp-a.pdf (di akses tanggal 16-022018)

Surya. 2016. Program Keselamatan dan Kesehatan Kerja untuk Mendorong Produktivitas dan Daya Saing http://www.sep.co.id/id/masyarakat/ke sehatan-keselamatan/ (di akses tanggal 13-02-2018)

Sutrisno, dkk. 2010. Keselamata, kesehatan kerja dan lingkungan hidup . jakarta: PT. Toko yudhistira.

Tarkawa. 2008. Keselamatan dan kesehatan kerja manajemen dan implementasi $\mathrm{k} 3$ di tempat kerja . surakarta : Harapan press.

Utaminingsih, S., \& Candra, A. (2015). Penentuan Lama Waktu Istirahat Berdasarkan Beban Kerja Dengan Menggunakan Pendekatan Fisiologis Disaint JOHN'S SCHOOL BSD. Teknologi, Jurnal Ilmiah dan teknologi, Fakultas Teknik Dan Fakultas MIPA Universitas Pamulang, 11(29), 1-12.

Wahyu, Tri. 2017. Kategori Umur Menurut Depkes

RIhttps://kupdf.com/download/kategor i-umur-menurut-depkes-

ri_58b4e7fe6454a7fb40b22af9_pdf.

(di akses tanggal 13-02-2018)

Wahid Kurniawan. 2017. Hubungan Faktor Karakteristik Pekerja, Safety Morning Talk (Smt) Dan Housekeeping Dengan Kejadian Minor Injury Pada Pekerja Di Proyek Pembangunan Gedung Kantor Pt. X Jakarta Https://Media.Neliti.Com/Media/Publi cations/163313-ID-Hubungan-FaktorKarakteristik-Pekerja-Sa.Pdf (di akses tanggal 03-04-2018)

Winarsunu, Tulus. 2008. Psikologi kesehatan kerja. Malang: unuversitas muhammadiah malang. 